\title{
Design of a Low-Cost DNA Biochip Using Copper Electrode
}

\author{
Motasem Ghanim and Mohd Zaid Abdullah ${ }^{1, *}$ \\ Collaborative Microelectronic Design Excellence Centre (CEDEC), SAINS@USM, \\ Level 1, Block C, No. 10 Persiaran Bukit Jambul, 11900 Bayan Lepas, Penang, Malaysia \\ ${ }^{1}$ School of Electrical and Electronic Engineering, Universiti Sains Malaysia, \\ Engineering Campus, 14300 Nibong Tebal, Penang, Malaysia
}

(Received February 16, 2015; accepted July 28, 2015)

Key words: lab-on-chip, amperometry, DNA biosensors, microchip capillary electrophoresis, copper electrode

The need for affordable and disposable DNA biochips that can perform in situ analysis is increasing daily. Amperometric detection (AD) is one of the most popular detection techniques used in DNA sensing. An important component of these biochips is the working electrode that needs to be carefully designed to achieve good sensitivity. At present, most $\mathrm{AD}$ biochips use platinum $(\mathrm{Pt})$ or gold $(\mathrm{Au})$, since these materials are not only sensitive but also produce good signal-to-noise ratios. Hence, the cost of fabrication is a major factor since $\mathrm{Pt}$ or $\mathrm{Au}$ requires expensive machining technologies. As a tradeoff between cost and sensitivity, in this study, copper is used as an alternative material in designing the biochips. DNA sensing is performed using newly designed biochips, and the performance is compared with those from a Pt electrode. Results from this study suggest the feasibility of designing not only low-cost but truly disposable biochips for DNA sensing.

\section{Introduction}

Interest in electrochemical sensing is increasing dramatically. Recently, electrochemical detection (ECD) has become the most widely used method in biosensing applications. ${ }^{(1)}$ Currently, several detection methods that can be used for DNA detection in biomedical sensing applications are available. ${ }^{(2-4)}$ Amperometric detection is one such method commonly used in microchip capillary electrophoresis (MCE) systems, and this method is being used extensively in modern electrochemical applications. ${ }^{(5,6)}$ Portability, affordability, resolution, and other attractive features make electrochemical detection one of the most popular techniques for detecting DNA molecules or other electroactive analytes. Various factors have had a major impact on the performance of MCE. One

"Corresponding author: e-mail: mza@usm.my 
of them is the electrode material used. Various materials can be used for fabricating the electrode as well as other important elements in MCE, such as the substrate and microchannel. ${ }^{(1,7,8)}$

Electrodes that are responsible for electrochemical separation and/or detection can be made of several materials. ${ }^{(1)}$ These materials have a significant impact on the performance of MCE, and many researchers have focused on this area to achieve more stable and sensitive microchips with higher resolution. ${ }^{(7,9,10)}$ The most commonly used materials for working electrodes are gold $(\mathrm{Au})$ and platinum $(\mathrm{Pt}){ }^{(1)}$ Selecting a material for working electrodes is a very sensitive process. This is principally due to the requirement for measuring very low currents induced at the electrode surface due to redox reactions of the analytes. Generally, redox reactions produce currents on the order of a few picoamperes. This small current requires designers to be very sensitive when choosing the correct electrode material. ${ }^{(10)}$ Nevertheless, Pt and Au are very expensive especially for the production of disposable DNA detection microchips. Therefore, selecting an affordable alternative material that can deliver an acceptable performance becomes very important. Using affordable materials allows the bioanalytical application of the microchips to be broadened. In this study, a relatively novel microchip made from copper electrodes was developed and tested in the laboratory. The performance of this system was compared with that of a biochip fabricated with a Pt electrode. Copper $(\mathrm{Cu})$ was selected as an alternative material for three reasons. First, $\mathrm{Cu}$ is very cheap compared with noble metals. Second, it is widely available in the market. Third, and most importantly, the use of a copper electrode leads to a cheaper fabrication process, since expensive procedures, such as evaporation and sputtering, which are commonly associated with noble metals, can be completely avoided. In this study, experiments were performed to compare the performance characteristics of $\mathrm{Cu}$ and Pt electrodes, as well as to study the performance of a new biosensor in DNA detection. The results together with the improved performance of the system are presented and discussed.

\section{Microchip Design}

DNA amperometric detection microchips are mainly fabricated on two main substrates, nanely, the electrode and DNA separation microchannel substrates. In the process of designing microchip substrates, the three-dimensional computer-aided design (CAD) software package 'SolidWorks 2010' was used to design both layers of the microchip. This software provides user-friendly tools for CAD design and gives actual dimensions on the microscale. In addition, it can save files in e-drawing file format, which is compatible with most common printers.

\subsection{Substrate for electrodes}

The electrode design utilized $\mathrm{Pt}$ and $\mathrm{Cu}$ electrodes deposited over glass substrates using evaporation or sputtering techniques. Figure 1(a) shows a schematic diagram of the detection electrodes. As shown in the figure, the detection cell was composed of two groups of electrodes. Each group serves as a detection circuit and works independently. This allows the microchip to be used repeatedly compared with those having only one 


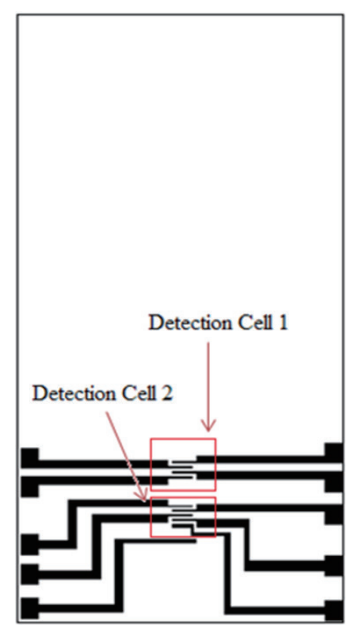

(a)

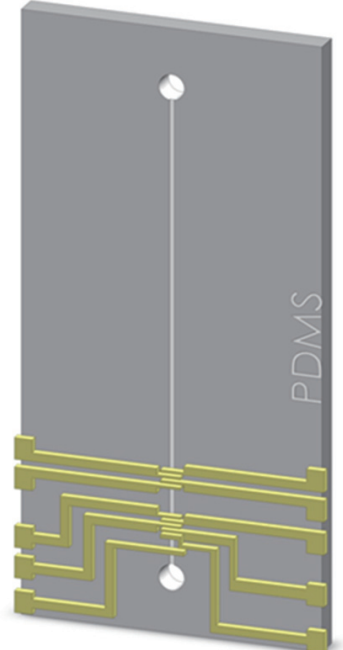

(b)

Fig. 1. (Color online) (a) Schematic diagram of the microelectrode array mask and (b) 3D design of both electrodes and PDMS.

detection cell. The biochip based on the Pt electrode can be used several times compared with once for the $\mathrm{Cu}$ electrode owing to contamination. Moreover, $\mathrm{Cu}$ electrodes are easily oxidized compared with Pt electrodes. Therefore, having spare electrodes to form additional detection cells will extend the microchip lifetime.

\subsection{Microchannel substrate}

The microchannel design is shown in Fig. 1(b). In this 3D design, two wells connected by a microchannel are also shown. In addition, the detection electrodes are aligned on top of the separation microchannel. The microchannel has the following dimensions: width $150 \mu \mathrm{m}$, depth $130 \mu \mathrm{m}$, and length $5 \mathrm{~cm}$. These dimensions were carefully selected to optimize the design.

\section{Fabrication Materials}

The microchip design is based on a polydimethylsiloxane (PDMS) and glass hybrid. The top layer containing the microchannel is made of PDMS. The advantages of using PDMS include transparency, ease of fabrication, high melting point after curing, stability, and flexibility. ${ }^{(11)}$ Moreover, PDMS can be made into a microscale structure and can easily be glued onto glass using plasma etching. The PDMS layer is $7 \mathrm{~cm}$ long and $3.5 \mathrm{~cm}$ wide. The bottom layer comprises a glass substrate onto which Pt electrodes 
are deposited by RF sputtering. These electrodes are etched using the standard photolithographic process. In this case, $\mathrm{Pt}$ is selected as an electrode material because of its unique features, such as good electrical conductivity and inertness to redox reactions. ${ }^{(12,13)}$ The design is based on an in-channel amperometric detection technique and consists of three $\mathrm{Pt} / \mathrm{Cu}$ sensing electrodes, namely, working, reference, and counter electrodes.

\section{Microchip Fabrication}

Figure 2 shows the procedure for fabricating the microchip consisting of PDMS and glass substrates. The solution used for cleaning the silicon wafer was Piranha $6: 1 \mathrm{H}_{2} \mathrm{SO}_{4} /$ $\mathrm{H}_{2} \mathrm{O}_{2}$. The wafer was coated with Negative Resist NR21-20000P using a spin coater. Then, it was placed in an oven for a specific period and later exposed to UV light to print the mask. The mold was ready for use after spraying with a developer. The PDMS was

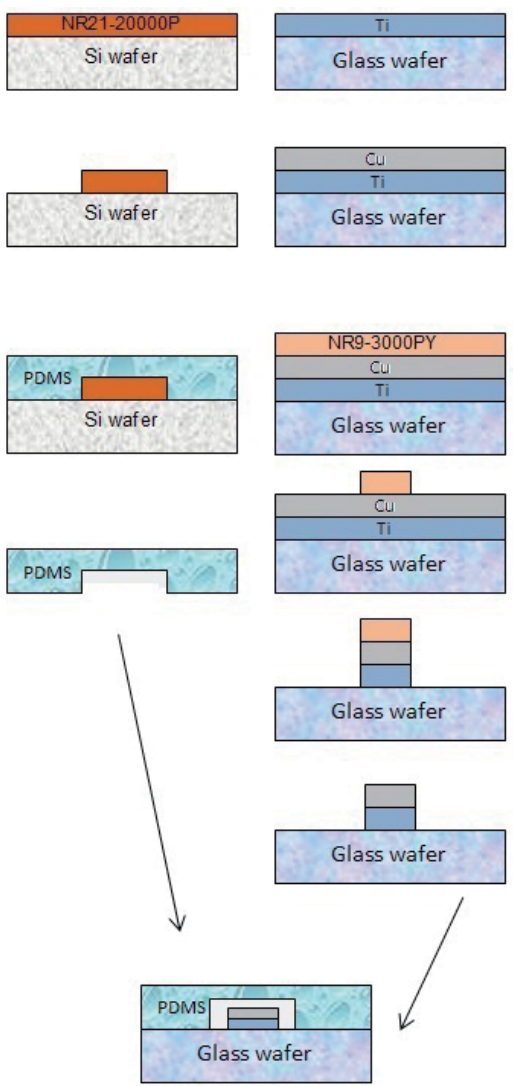

Fig. 2. (Color online) Fabrication procedure involving the base, PDMS, and electrode substrates. 
then poured into a mold forming the required channel. The PDMS was placed inside a vacuum at a pressure of $10^{-3}$ torr for $15 \mathrm{~min}$ to remove the bubbles from the PDMS liquid. Then, it was cured by placing in an oven at $200{ }^{\circ} \mathrm{C}$ for $2 \mathrm{~h}$. The cured PDMS was peeled off from the mold, after which reservoirs were made at each end of the microchannel using a $3 \mathrm{~mm}$ circular punch to form the required wells.

\section{Experimental Results}

Since oxidation/reduction potentials are material-specific, cyclic voltammetry (CV) experiments were separately performed for $\mathrm{Cu}$ and $\mathrm{Pt}$ electrodes. For the copper $\mathrm{CV}$ experiment, a mixture consisting of $1 \mathrm{mM}$ of DNA nucleotides, deoxyadenosine triphosphate (dATP) and deoxyguanosine triphosphate, was diluted in $0.1 \mathrm{M} \mathrm{KCl}$. The electrodes used were a $\mathrm{Ag} / \mathrm{AgCl}$ reference electrode, a $3 \mathrm{~mm} \mathrm{Cu}$ working electrode, and a $\mathrm{Pt}$ wire counter electrode. Data were gathered at a scan rate of $80 \mathrm{mV} / \mathrm{s}$ and recorded and stored in a personal computer connected to a potentiostat through a universal serial bus (USB) cable. Results from this experiment revealed a current-voltage response, which is shown graphically in Fig. 3. It can be observed from this figure that the nucleotides generated the best anodic and cathodic current peaks under potentials of 0.2 and -0.45 $\mathrm{V}$, respectively. Clearly from this graph, both cathodic and anodic reactions resulted in current sensitivities of comparable magnitudes. Therefore, any of these potentials could be used as the reference voltage in the detection experiments.

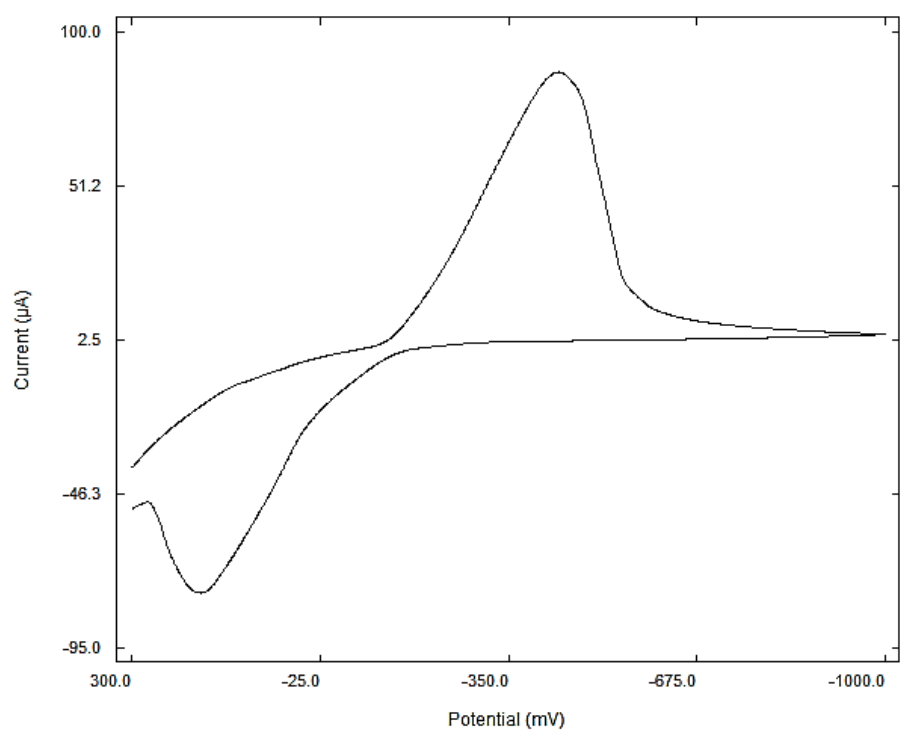

Fig. 3. Cyclic voltammograms produced by a $\mathrm{Cu}$ electrode using a mixture containing $500 \mu \mathrm{M}$ DNA nucleotides, which was diluted in $0.1 \mathrm{M} \mathrm{KCl}$ buffer solution. 
With similar settings, the CV experiment was repeated for the Pt working electrode. In this case, the nucleotide concentration was increased to $500 \mu \mathrm{M}$ because platinum electrodes were expected to present higher responses than copper electrodes. In this experiment, the best reduction reaction potential occurred when the electrode potential reached $-0.50 \mathrm{~V}$. This result is in agreement with similar findings reported earlier. ${ }^{(14)}$

Using the fabricated microchip, two experiments were performed using DNA amplicon samples one using $\mathrm{Pt}$ as working electrode and the other using $\mathrm{Cu}$. This enabled a comparison of the sensitivity and performance of DNA detection by these electrode materials. The detection potentials applied in these experiments were determined depending on the results of cyclic voltammetry experiments. For the Pt electrode, the reduction potential applied between the working and reference electrodes was $-0.5 \mathrm{~V}$, whereas $-0.45 \mathrm{~V}$ was set for the $\mathrm{Cu}$ electrode. Therefore, both electropherograms contained cathodic peaks only. ${ }^{(13)}$

Figure 4 shows the individual current responses produced during amperometric detection using (a) Pt and (b) $\mathrm{Cu}$ as the working electrodes. For both experiments, the separation time was $10 \mathrm{~min}$, and the separation voltage was $125 \mathrm{~V}$ corresponding to an electric field strength of $25 \mathrm{~V} / \mathrm{cm}$. The percentage of agarose gel solution was $2.0 \%$, and the same single-band DNA amplicon sample was used in both experiments. ${ }^{(15)}$ As clearly seen in the figure, the reaction was successfully detected with a current amplitude

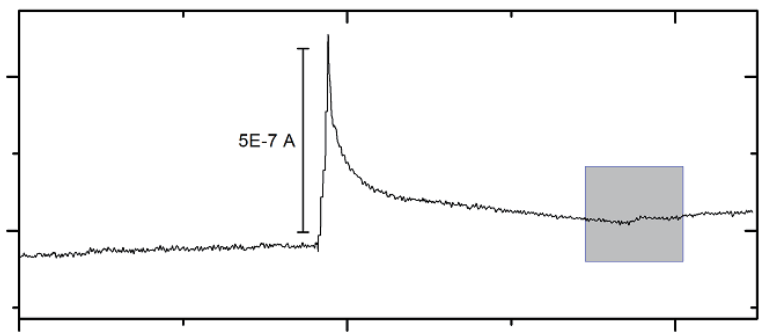

(a)

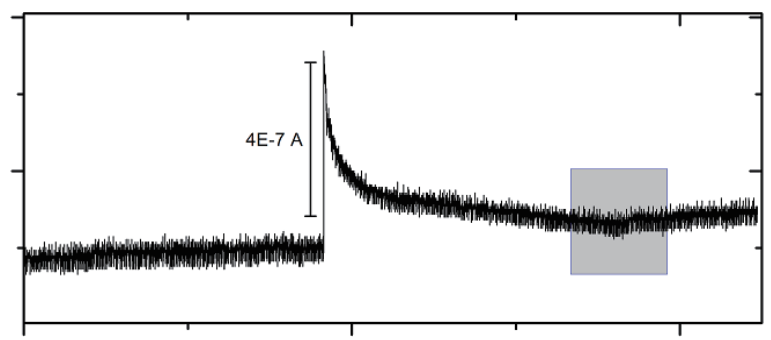

(b)
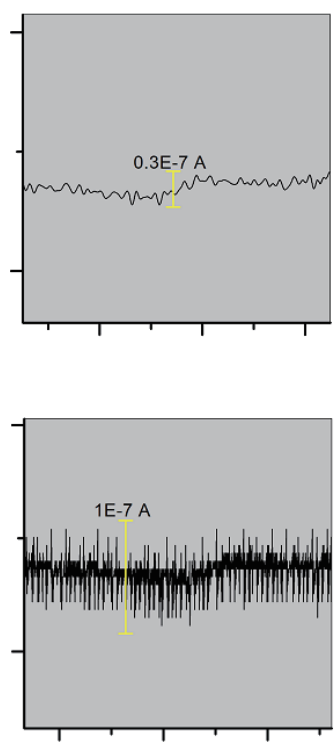

Fig. 4. (Color online) Electropherograms of (a) $\mathrm{Pt}$ and (b) $\mathrm{Cu}$ working electrodes generated by current responses during the amperometric detection of a single-band DNA amplicon. 
significantly greater than the noise floor. A close examination of Fig. 4 reveals that the Pt electrode showed a higher response than the $\mathrm{Cu}$ electrode. Moreover, as shown on the right-hand side of each electropherogram, the ripple noise produced by the $\mathrm{Cu}$ electrode was about $0.1 \mu \mathrm{A}$ compared with $0.03 \mu \mathrm{A}$ for Pt. This means that the ripple noise produced by $\mathrm{Pt}$ is threefold much lower than that produced by $\mathrm{Cu}$. Although the $\mathrm{Pt}$ electrode has shown a much higher performance than the $\mathrm{Cu}$ electrode, the peak appearing on the electropherogram of the $\mathrm{Cu}$ electrode is clearly recognizable. Moreover, the peak delivers the same information as the Pt electrode, since both indicate the presence of signals due to DNA. Therefore, it is experimentally possible to use $\mathrm{Cu}$ instead of $\mathrm{Pt}$ as a working electrode in DNA sensing.

To explore more features of the microchip, one further experiment was performed using a separation voltage of $20 \mathrm{~V} / \mathrm{cm}$ and an agarose gel percentage of $2.0 \%$. In this experiment, a real DNA sample was used to characterize the performance of the $\mathrm{Cu}$ working electrode in real DNA detection. The DNA sample consisted of nine groups (bands) as shown in Fig. 5. The sample volume was $4 \mu 1$, and the concentration of DNA fragments was $0.1 \mu \mathrm{g} / \mu \mathrm{l}$. The electropherogram of this experiment is shown in Fig. 6. Similarly to the other case, all nine DNA bands were detected successfully by the microchip.
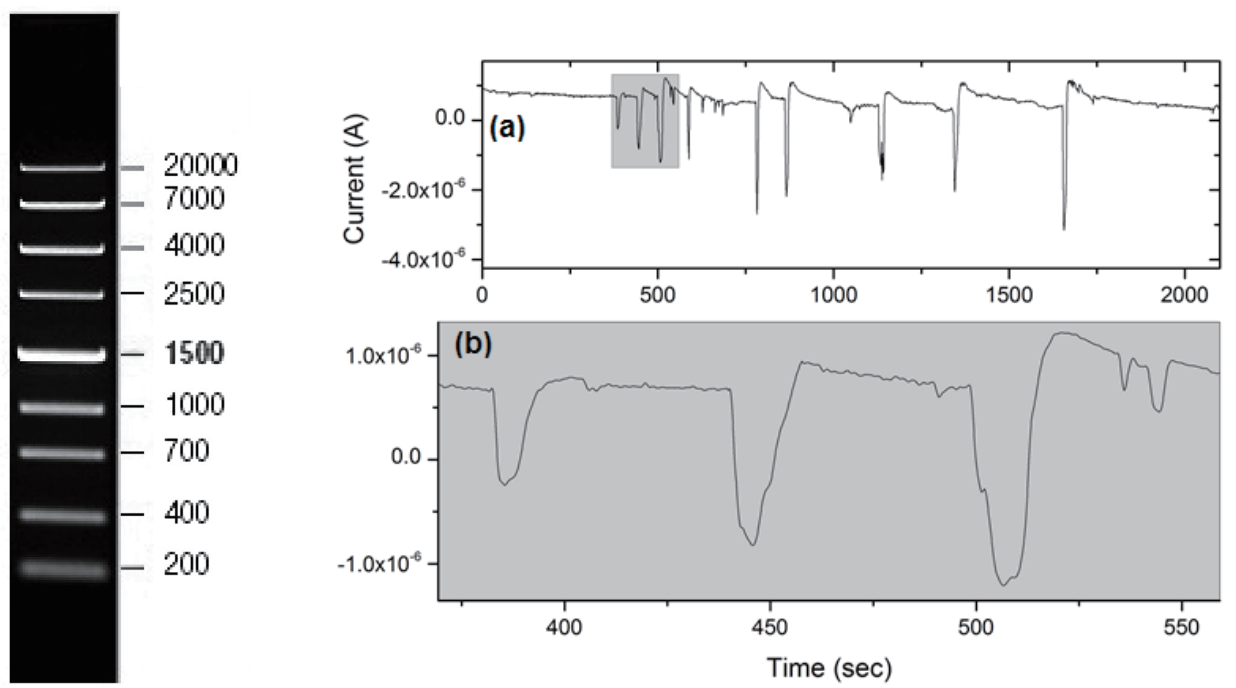

Fig. 5 (left). Electrophoretic bands of DNA marker 200-20000 bp DNA ladder 2 (ZipRuler ${ }^{\mathrm{TM}}$ Express).

Fig. 6 (right). (a) Electropherogram of ZipRuler ${ }^{\mathrm{TM}}$ Express produced by the PCB/PDMS microchip and (b) close-up view of the shaded region in (a). 
In this experiment, the sensitivity and accuracy of the microchip are demonstrated. The results were compared with the DNA bands obtained by conventional electrophoresis as shown in Fig. 5. In this figure, the DNA bands are arranged according to the size of the DNA fragments; the first and last bands correspond to the longest and shortest fragments, respectively. The sample well is located at the top.

It can be seen from Fig. 5 that this DNA ladder consists of nine equally separated bands with sizes ranging from 200 to $20000 \mathrm{bp}$. The electropherogram generated by the microchip is shown in Fig. 6; the first impulse corresponds to a band labelled $200 \mathrm{bp}$, the second impulse corresponds to a band labelled $400 \mathrm{bp}$, and so on. Hence, the first impulse represents the shortest DNA fragments, which travelled faster than the other fragments. Smaller DNA fragments are lighter in weight and hence move freely inside a porous medium, such as the agarose gel used in this experiment. Thus, the bands appearing nearer the receiving well at the top of the lane in Fig. 5 belong to heavier DNA fragments compared with the lighter DNA fragments whose bands appeared relatively far from the receiving well.

Comparing Figs. 6 and 5, it is obvious that the data obtained by conventional gel electrophoresis and the microchip fabricated using $\mathrm{Cu}$ electrodes are similar. Each impulse in the electropherogram corresponds to a single band in the gel electrophoresis; the numbers, including the sizes, are in full agreement. This experiment has proved that $\mathrm{Cu}$ electrodes can separate and detect DNA fragments successfully. Principally, this shows that it is possible to use the affordable $\mathrm{Cu}$ material to manufacture microchips for DNA detection, and that $\mathrm{Cu}$ is a good alternative material for producing the working electrode for DNA detection.

\section{Conclusions}

In this study, the performance of a biochip utilizing an electrode made of copper was tested in DNA detection experiments. The biosensor performance was investigated using two types of DNA samples. Experiments were also performed using the biochip with standard Pt electrodes for comparison. Results indicated that the performance of $\mathrm{Cu}$ electrodes is comparable to that of Pt electrodes in terms of current sensitivity and run time. On average, the biochip takes approximately $1800 \mathrm{~s}$ to completely separate DNA fragments with sizes ranging from 200 to $20000 \mathrm{bp}$. It was also observed that the biochip with the copper electrode produced a sufficiently strong response to oxidation or reduction reactions in comparison with the Pt electrodes. The signals produced by the $\mathrm{Cu}$ electrodes are relatively noisy; however, such electrodes delivered the same information as the Pt electrodes. Therefore, $\mathrm{Cu}$ is a good alternative electrode material in DNA biosensing applications. Designing Cu-based biochips is relatively faster and less costly, since it does not require the use of expensive methods, such as sputtering and evaporation. This means it may be feasible to produce a low-cost and disposable biochip, thereby, extending applications to other biosensitive materials and chemical analytes. 


\section{Acknowledgements}

This work has been supported by a Universiti Sains Malaysia (USM) Research University Grant number: 814024.

\section{References}

1 M. H. Ghanim and M. Z. Abdullah: Talanta 85 (2011) 28.

2 J.-J. Xu, A.-J. Wang and H.-Y. Chen: TrAC Trends Anal. Chem. 26 (2007) 125.

3 H. Aoki, A. Kitajima and H. Tao: Sens. Mater. 22 (2010) 327.

4 Y. Yamamoto, K. Maehashi, Y. Ohno and K. Matsumoto: Sens. Mater. 21 (2009) 351.

5 X. Xu, L. Li and S. G. Weber: TrAC Trends Anal. Chem. 26 (2007) 68.

6 K. Maehashi and K. Matsumoto: Sens. Mater. 21 (2009) 363.

7 D. J. Fischer, M. K. Hulvey, A. R. Regel and S. M. Lunte: Electrophoresis 30 (2009) 3324.

8 M. L. Rodríguez-Méndez, C. Apetrei, C. Medina-Plaza, R. Muñoz and J. A. de Saja: Mater. Sens. 5 (2014) 139.

9 A. L. Eckermann, D. J. Feld, J. A. Shaw and T. J. Meade: Coord. Chem. Rev. 254 (2010) 1769.

10 M. Pumera, A. Merkoçi and S. Alegret: Electrophoresis 28 (2007) 1274.

11 J.-H. Kim, K.-H. Na, C. J. Kang, D. Jeon and Y.-S. Kim: Microelectron. Eng. $73-74$ (2004) 864.

12 M. H. Ghanim, K. Hasan, N. Najimudin and M. Z. Abdullah: Proc. Int. Conf. Biomed. Health Inf. (BHI) 2012 (IEEE-EMBS, Hong Kong, 2012) p. 1005.

13 M. Ghanim and M. Z. Abdullah: BioChip J. 7 (2013) 51.

14 M. H. Ghanim, N. Najimudin, K. Ibrahim and M. Z. Abdullah: IET Nanobiotechnol. 8 (2014) 77.

15 M. H. Ghanim and M. Z. Abdullah: Int. Conf. Health Inf., ed. Y.-T. Zhang (Springer International Publishing, Vilamoura, 2014) p. 132. 